\title{
Tobacco Use Among Long Route Bus Drivers and Staffs of Dharan Eastern Nepal a KAP Study
}

\author{
Giri Saroj ${ }^{1, ~ *, ~ C h a u d h u r i ~ S o n a i ~}{ }^{1}$, Yadav Ashok Kumar ${ }^{1}$, Yadav Ajay Kumar ${ }^{1}$, Shrestha Shree Ram ${ }^{1}$, \\ Baral Dharani Dhar ${ }^{2}$
}

${ }^{1}$ Department of General Practice and Emergency Medicine, B. P. Koirala Institute of Health Sciences, Dharan, Nepal

${ }^{2}$ Department of Community Medicine and SPH, B. P. Koirala Institute of Health Sciences, Dharan, Nepal

Email address:

dr.sarojgiri@gmail.com (G. Saroj)

${ }^{*}$ Corresponding author

\section{To cite this article:}

Giri Saroj, Chaudhuri Sonai, Yadav Ashok Kumar, Yadav Ajay Kumar, Shrestha Shree Ram, Baral Dharani Dhar. Tobacco Use Among Long Route Bus Drivers and Staffs of Dharan Eastern Nepal a KAP Study. Science Journal of Public Health. Vol. 5, No. 4, 2017 , pp. $301-306$. doi: $10.11648 /$ j.sjph.20170504.14

Received: March 27, 2017; Accepted: June 7, 2017; Published: June 15, 2017

\begin{abstract}
Tobacco use remains a major cause of preventable deaths worldwide. WHO estimated that about $25 \%$ of Nepalese population smokes. In Nepal it is widely believed that tobacco use among bus drivers and staffs is very high. This descriptive cross sectional study was conducted in Dharan bus station among 300 bus drivers and staffs who voluntarily responded with self-administered questionnaire to estimate the prevalence of tobacco consumption and to assess their knowledge, attitude and practice regarding tobacco use. Prevalence of tobacco consumption among the respondents was $96.3 \%$. Tobacco initiation at the age $<18$ years was $52 \%$. 'Peer pressure' and 'Influenced by family member(s)' were the reasons for initiation while 'Like the intoxicated feeling' $(67.5 \%)$ and 'Feeling Mature' for continued use. Respondents (97\%) claimed they knew about the injurious effect of tobacco use, diseases cited being respiratory, cancer and cardiac, but only $48.9 \%$ knew this before initiating its use. A $75.8 \%$ of tobacco consumers had tried to quit it due to 'Health issue' $(65.3 \%)$ followed by 'Pressure from family member/s' and 'Economic burden'. Only about $20 \%$ were successful in quitting. The main reason for failure was feeling of addiction (69.7\%). Among current tobacco users, $95 \%$ would like to seek medical help in quitting, if available. Our study concluded that the prevalence of tobacco consumption among bus drivers and staffs was very high. More than half started its use at age $<18$ years without prior knowledge of harmful effects of tobacco use. Majority would like to seek medical help as they have failed quitting it due to feeling of addiction. Targeted programs such as nicotine replacement clinics would be highly effective for them with desire to quit tobacco use with medical help.
\end{abstract}

Keywords: Tobacco Use, Bus Drivers, Eastern Nepal, Knowledge Attitude Practice

\section{Introduction}

'Tobacco use (smoke and smokeless) remains a major cause of preventable deaths worldwide accounting about six million people each year with many of these deaths occurring prematurely.' [1] Tobacco consumption (TC) is not only associated with ill-health, disability and death from noncommunicable chronic diseases, it also increases risk of death from communicable diseases. Despite its global burden, tobacco still is a legal drug. The endorsement of MPOWER package measures introduced by World Health Organization (WHO) in 2008 (where M: Monitoring tobacco use and prevention policies; P: Protecting people from tobacco smoke; O: Offering help to quit tobacco use; W: Warning about the dangers of tobacco; E: Enforcing bans on tobacco advertising, promotion and sponsorship, and R: Raising taxes on tobacco) in law, are still the issues imposing challenges for their implementation. 'Report of WHO points the unavailability of Programs to offer help to quit tobacco use as a potential field to improve in Nepal.' [2]

'In 2015, WHO estimated that about $21.5 \%$ of Nepal's population among which $34.9 \%$ of men and $9.8 \%$ of women 
smoked.' [1] Though there is no exact data about burden of smokeless tobacco use, a national Global Youth Tobacco Survey (GYTS) in 2007 reported that overall $7.9 \%$ of the students ever smoked cigarettes and $8 \%$ used other tobacco products. [3] Similarly, Nepal Adolescents and Youth Survey (NAYS) published in 2012 revealed 13\% of adolescents and youth ever used smoking or smokeless tobacco and $6 \%$ used illicit drugs. [4] As noted by Sinha et al [5] in 2012, prevalence of smokeless tobacco was $18.6 \%$ among adults aged 15-64 years; $31.2 \%$ among males and $4.6 \%$ among females. 'A study conducted comparing the tobacco use among youth of Bangladesh, Nepal and Srilanka revealed prevalence is high in Nepal (9.4\%) than Bangladesh (6.9\%) and Srilanka $(9.1 \%)$ but the age of initiation of tobacco use was the highest among Nepali youth (10.24 yrs.) compared with Bangladeshi (9.6 yrs.) or Srilankan (8.61 yrs.).' [6] 'The age of initiation of tobacco use in Nepal is early to late adolescence.' [7], [8], [9], [10], [11] Although the result of NAYS (2012), 93\% adult and youth expressed their confidence to give up alcohol/tobacco/drug, a study conducted by Aryal et al [9] concluded that the smoking susceptibility among adolescents in a peri-urban area of Nepal is as high as $50 \%$.

'Factors like education, occupation, influence from media, movies and family members, for stress relief, pleasure during tobacco use, better self-esteem and occupational boredom are associated with tobacco use. Similarly, reasons for not quitting tobacco use being unaware of the adverse effects of its use, lack of information or methods of quitting, lack of motivation to quit and unsuccessful attempts.' [7], [8], [9], [10], [11], [12], [13], [14], [15]

Though there are no sufficient studies to support the notion, it is widely believed in Nepal that bus drivers and staffs are one of the high risk occupational groups for TC. Sreeramareddy et al [16] in 2011 concluded that prevalence of TC is significantly high in Nepalese people especially in Kathmandu valley and eastern regions. The current study was conducted in Dharan, which is situated in eastern part of Nepal. Khanal et al [12] pointed out that lower education and manual work were more likely to be associated with TC. Furthermore, most of the helping staffs of the long route buses are male of young age group with low education level.

This study was conducted among 'the long route bus drivers and staffs' to assess the prevalence and to know their knowledge, attitude and practice regarding tobacco use. The result will be helpful in finding out the prevalence and attributing factors for tobacco use thus filling in the gaps between the KAP of this study population and the existing anti-tobacco programs.

\section{Methods}

\subsection{Type and Setting of the Study}

This is a descriptive cross sectional study conducted among 300 bus drivers and staffs of long route bus departing from Dharan bus station using a self-administered questionnaire.

\subsection{Inclusion Criteria}

Bus drivers and staffs with minimum one year of experience and willing to participate in the study.

\subsection{Measurement}

The questions were categorized into demographic profile, TC behavior, knowledge regarding injurious effects of TC, attitude regarding TC and willingness for quitting.

\subsection{Sample (Data Collection)}

An official letter was issued from BP Koirala Institute of Health Science requesting to help in the study and sent to Yatayat Vewashahi Sangh (Transport Corporation). All the required data like bus routes, bus numbers, staffs list etc. were obtained. An information sheet was provided and explained by one of the members from research team during interview. A written consent of participants in the study was taken with confidentiality, thus encouraging the participants to give true answers. Furthermore, participants were assured that it's a voluntary and they can quit from the study at any time without penalty or loss. Responses of illiterate respondents were filled up by a member of the research team. Pretest was done in $10 \%$ of the sample size.

\subsection{Operational Definitions}

For the purpose of this study, the following operational definitions are used-

'Long route bus drivers' means drivers of the buses departing from Dharan Bus Park on night service basis. 'Bus Staffs' means conductor, helper and any assistant driver of that bus. 'Tobacco use' means consumption of tobacco in any form, i.e. smoke or smokeless. 'Ever user' is a person who had consumed tobacco product any time in past but did not use regularly. 'Current users' are the persons who currently consume tobacco. 'Past user' is someone who had consumed tobacco in smoking or smokeless form regularly but has not used it from 1 month back to the point of filling questionnaire. 'Non user' is person who had never used tobacco in any form as of the day of completing the questionnaire.

\subsection{Data Analysis}

Collected data were entered in Microsoft excel 2007 and converted into SPSS for statistical analysis. Descriptive statistical like percentage was calculated. For inferential statistics, chi square test was applied to find out the significant between dependents and other related variables at $95 \%$ CI, where $\mathrm{p}=0.05$.

\subsection{Ethical Consideration}

Ethical clearance from Institutional Research Committee was obtained before starting the study. 


\section{Results}

All respondents were male ranging from 18 years to 53 years (mean age 30.8 years).

Table 1. Demographic profile of respondents.

\begin{tabular}{llll}
\hline Characteristics & Categories & $\begin{array}{l}\text { No of } \\
\text { Respondent }\end{array}$ & Percentage (\%) \\
\hline \multirow{3}{*}{ Age groups in } & $\leq 25$ & 89 & 29.7 \\
years & $26-30$ & 66 & 22.0 \\
& $36-45$ & 53 & 17.7 \\
& $>40$ & 45 & 15.0 \\
& Illiterate & 47 & 15.7 \\
Education level & Literate & 17 & 5.3 \\
& Secondary level & 93 & 57.7 \\
& Intermediate level & 17 & 31.0 \\
& $\geq$ Bachelor level & 1 & 5.7 \\
\hline
\end{tabular}

Among the respondents, 245 (81.7\%) were 'current users', $44(14.6 \%)$ were 'past users' and 11 (3.7\%) were 'non-users'. Among those who used it, 52\% started at the age $<18$ years and $48 \%$ at the age $>18$ years and $70 \%$ of them also consumed either alcohol $(87.2 \%)$ or other illicit drugs $(12.8 \%)$.

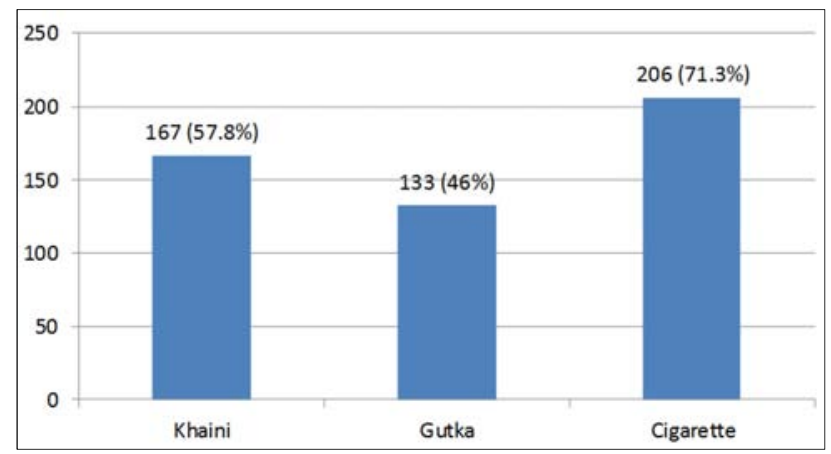

Figure 1. Type of Tobacco used by respondents (khaini and gutka are chewing forms).

Reasons for Initiation of tobacco use were mostly seen as 'peer pressure' (31\%) followed by 'influenced by smoking habit of family members/relatives' (15.2\%), 'due to curiosity' $(14.9 \%)$ and for continuation of tobacco use was for 'enjoying the intoxicated feeling' (67.5\%), 'feeling mature' $(22.5 \%)$, 'relief from stress'( $8 \%)$. Also, $75.8 \%$ had tried quitting the use of tobacco. Their reasons mainly were 'due to health issue' $(65.3 \%)$, 'pressure from family member/s' (21.5\%), 'economic burden' (11.9\%) and 'not liking the use' (1.4\%). Among them, $79.9 \%$ were unable to quit its use due to 'feeling of addicted to tobacco use' $(69.7 \%)$ and 'seeing others use it' $(27.4 \%)$. Our study revealed that $66.3 \%$ smokers have tried more than four times to quit its use. Again, 97\% responders knew about the injurious effect of tobacco use but only $48.9 \%$ knew this before starting its use. Among those who didn't know the injurious effect of TC on health before its initiation, 90\% would not have used it if they had prior knowledge and 95\% of current tobacco consumers would like to quit tobacco use with medical help.

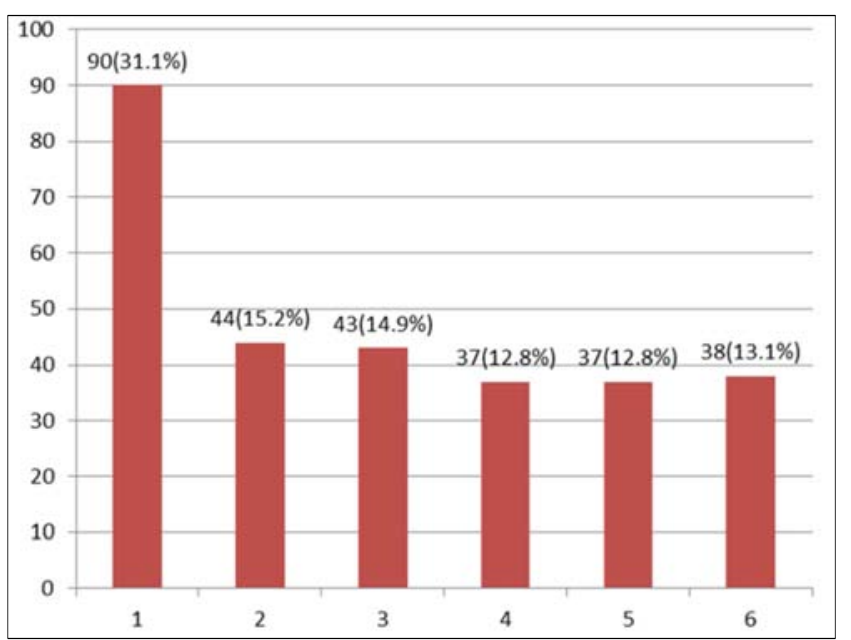

Figure 2. Reasons for Initiation of tobacco use (1=Peers pressure, $2=$ Due to curiosity, $3=$ Influenced from family members/ relatives, $4=$ Influenced from cinema / as fashion, $5=$ To feel mature, $6=$ Others).

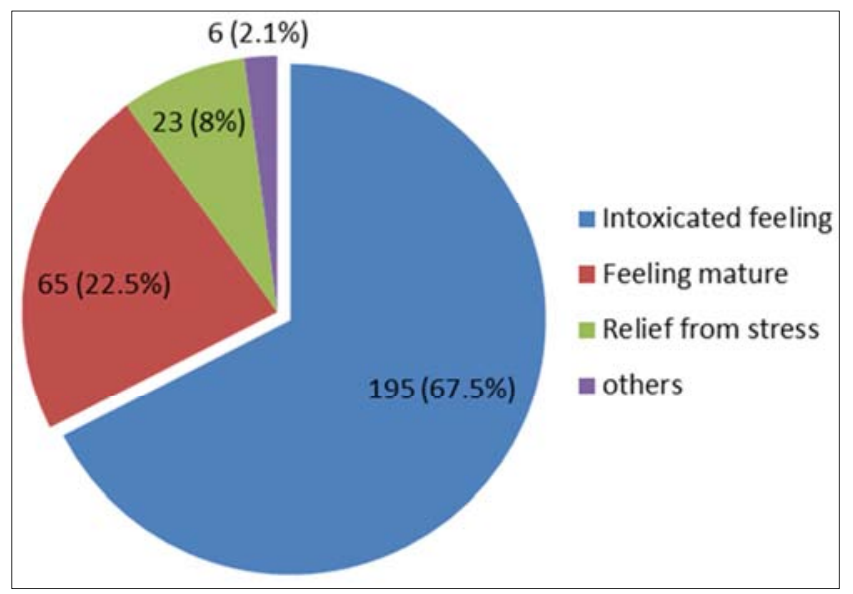

Figure 3. Reasons for continuation of Tobacco consumption.

\section{Discussion}

The prevalence of both 'ever use' and 'current use' of tobacco in present study group was quite high $(96.3 \%$ and $81.7 \%$ respectively), unlike the results of studies done among adolescent students from Dharan $(19.7 \%$ and $16.46 \%$ respectively), college students $(34.2 \%$ and $17 \%$ respectively), employee of a university hospital ('ever smoker' $33.6 \%$ and 'current smoker' 13.6\%), Nepalese men ('current smoker' $33.6 \%$ and 'current smokeless tobacco chewer' $34.8 \%$; and among women in Dharan (current smoker' $12.9 \%$ and 'current smokeless tobacco use' 14.1\%). [7], [12], [17], [18], [19] The prevalence of TC estimated by Kabir et al [6] on 2013 using the data of GYTS also varied widely to the result of current study ( $9.4 \%$ versus $96.3 \%$ ).

The variation in prevalence of tobacco consumption in our study population and other population may be because of the fact that the drivers and the bus staffs usually are away from home for their work, mostly with their colleagues in bus or in bus station. This is supported by the finding of current study which showed the major cause of initiation of TC to be 'peers pressure' $(31 \%)$ and the major cause of continuation 
of TC to be 'enjoying the intoxicated feeling' (67.5\%). Therefore, a bus station acts as a fertile land for the initiation and continuation of TC. Second most common reason for tobacco initiation was 'influenced by smoking habit of family members/ relatives' $(15.2 \%)$ which was found to be in consistent with other studies. [6], [9], [13] Similarly, second most common reason cited for continuation of its use is 'to feel mature' $(22.5 \%)$, which is comparable with the studies done among college students from western Nepal. [17], [20] More than half of our tobacco consuming respondents initiated tobacco consumption due to peers pressure and mimicking family members and relatives, even before they knew the harmful effect of TC on health. In more than half of them, the habit persisted due to feeling addicted to its use. It clearly shows a need of preventive measures like health education regarding harmful effects of tobacco use, creating tobacco free homely environment and preventing minors from tobacco exposure. In contrast to our study, some researchers noted the reasons for TC to be 'for refreshment', 'coping stress' and 'abundant leisure time/boredom. [13], [15], [21] The reasons may differ to some extent due to difference in study population. 'Among those who work shift duties, more than half used tobacco to cope with stress' [15] while respondents from a study conducted in China in 2013 revealed that 'though knowledge and lack of motivation plays a vital role, social and cultural factors were the main barrier for quitting TC.' [21]

Our result showed that more than half of the respondents $(52 \%)$ initiated tobacco use at the age less than 18 years, in line with the results of previous studies. [7], [10], [17], [20], [22] Some authors argue that there is a recent downward shift of age of initiation of tobacco use (10-13 years). [6], [7], [17] Most of those studies were done among school and college students, thus may have impacted in the result of early initiation of tobacco use. However, a study done by Choe et al [8] (in 5 south Asian countries including Nepal) concluded that only $35 \%$ of study group initiated tobacco use under the age of 20 years.

Among the responders who consume tobacco, more than three fourth $(75.8 \%)$ tried to quit its use. This positive attitude was also noted in a study conducted among college students from Gaza Palestine (81\%) and from western Nepal $(64.7 \%)$. [17], [23] In contrast to the result of current study, the percentages of respondents who tried to quit TC were less than a half in other studies. [10], [20] Echer et al [18] concluded that respondents in their study were motivated and desired to quit TC.

Despite the high percentage of respondents who tried to quit TC, only about 20 percentage succeeded quitting it in our study. The respondents failed to quit TC due to 'feeling addicted' (69.7\%). Results of other studies showed only some proportion of the respondents to have developed addiction' [10], [20] but a study conducted among 816 college students from western Nepal showed $43.1 \%$ feel addicted to TC. [17] The percentage of respondents trying to quit TC in current study $(66 \%)$ and the times attempted does not have similarity to other studies. [10], [23] Health concern was the main reason $(65.3 \%)$ among those who tried to quit TC. Early age of initiation, use of multiple tobacco products and concurrent use of other drugs may have played a vital role for adverse effect on health, and it increases attempts at quitting TC among the respondents using tobacco in our study. The result of the study conducted by Echer et al [18] in 2011 also showed that health concern was the main reason for attempts to quit tobacco. Though the percentage is very low, there were some respondents who did not like the tobacco use and did quit it. The major reasons for attempts to quit TC may be used for effective planning of tobacco control programs.

At the time of interview, $97 \%$ of the respondents of current study claimed they know the adverse effects of TC on health, which is quite higher than the results from other studies. [15], [22] On probing the diseases caused by TC, majority of the respondents mentioned respiratory, cancer and cardiac diseases in descending order. Very few of them had idea about mental illness and gastrointestinal diseases caused by TC. More than half $(51.1 \%)$ of the respondents who consume tobacco had no knowledge of injurious health effects of TC on initiation, otherwise $90.2 \%$ of them would not have had initiated. This result may give an opportunity in formulation of tobacco control plans and policies to improve their scientific knowledge and decreasing TC.

'Almost all (93\%) adolescents and youths of NAYS (2010/11) express confidence among themselves not to use tobacco or other drugs' while other authors had different views. [4], [10], [23] Our study showed that the respondents were highly motivated to quit tobacco consumption with some medical help (95.1\%). Despite high motivation and desire among the respondents of current study, they failed to quit TC due to physical and psychological dependence or feeling of addiction. Simple steps in assisting the quitting of TC can have a dramatic decline in the prevalence of TC among this high risk population group.

\section{Limitations}

Sample size was small and limited to Dharan bus station so it cannot be generalized to that occupational group. The responses given by the respondents were believed to be true for the assessment of tobacco use. It was not validated by use of any biomarkers. Further multi centered studies including greater sample size and using biomarkers for assessment of tobacco use is advised to be conducted to know the exact burden of TC among bus drivers and staffs.

\section{Conclusion}

Our study concluded that the prevalence of tobacco consumption among bus drivers and staffs was very high among whom more than a half initiated its use at the age less than 18 years without the knowledge of injurious effects on health. Most of the respondents would not have initiated TC if they had prior knowledge about it. The respondents were highly motivated to quit tobacco and had tried to quit it too 
but failed due to feeling addicted to its use. Almost all would like to quit TC with some medical assistance.

\section{Recommendation}

Government policies to ban free sale of tobacco to minor age group, smoking on public places, on tobacco advertisement and promotion, though amended in law, are still issues to be properly and strictly implemented. Targeted programs such as nicotine replacement clinics would be highly effective for such vulnerable group who desire to quit TC with medical assistance.

\section{Acknowledgments}

Authors are thankful to all the participants of the study for their valuable contribution. The study would not have been possible without their co-operation. Authors would like to sincerely thank Prof. Dr. G. Malla and Prof. Dr. BK Rai for their regular inspiration for conducting this study. Authors are also thankful to Dr. Sanjay Gupta and Dr. Alok Kumar for their help in data collection.

\section{References}

[1] WHO. WHO global report on trends in prevalence of tobacco smoking 2015. Available from:

http://apps.who.int/iris/bitstream/10665/156262/1/978924156 4922 eng.pdf. Accessed on- $5^{\text {th }}$ December, 2015.

[2] WHO. Report on the Global Tobacco Epidemic, 2013. Available from:

http://apps.who.int/iris/bitstream/10665/85380/1/9789241505 871_eng.pdf. Accessed on- 5th December, 2015.

[3] Pandey MR, Pathak RP, Shrestha S, Saud S. National Global Youth Tobacco Survey (GYTS) and National Global School Personnel Survey (GSPS) in Nepal (2007). Available from: http://www.searo.who.int/entity/noncommunicable_diseases/d ata/nep_gyts_report_2007.pdf?ua=1. Accessed-10 $\mathrm{Feb} 2016$.

[4] Ministry of Health and Population. Nepal Adolescents and Youth Survey 2010/11. Available from: http://nepal.unfpa.org/sites/default/files/pubpdf/NepalAdolescentandYouthSurveyHighlights\%282\%29.pd f. Accessed- 7 Feb 2016.

[5] Sinha DN, Bajracharya B, Khadka BB, Rinchen S, Bhattad VB, Singh PK. Smokeless tobacco use in Nepal. Indian journal of cancer 2012; 49(4); p: 352-6.

[6] Kabir MA, Goh KL, Khan MH. A cross-country comparison of tobacco consumption among youths from selected SouthAsian countries. BMC Public Health 2013; 13:379 Available from: http://bmcpublichealth.biomedcentral.com/articles/10.1186/14 71-2458-13-379. [ Accessed:15th dec.2015].

[7] Pradhan PMS, Niraula SR, Ghimire A, Singh SB, Pokharel PK. Tobacco use and associated factors among adolescent students in Dharan, Eastern Nepal: a cross-sectional questionnaire survey. Bmjopen 2013. 3 (2). Available from: http://bmjopen.bmj.com/content/3/2/e002123.full. [Accessed: 6th December 2015].
[8] Choe MK, Thapa S, Podhisita C, Raymundo C, Lin HS, Achmad S. The Teen Tobacco Epidemic in Asia: Indonesia, Nepal, Philippines, Taiwan, and Thailand. Journal of Youth Studies 2004. 7 (1). P: 73-87.

[9] Aryal UR, Petzold M, Bondjers G, Krettek A. Correlates of smoking susceptibility among adolescents in a peri-urban area of Nepal: a population-based cross-sectional study in the Jhaukhel-Duwakot Health Demographic Surveillance Site. globalhealthaction 2014. 7 (2014). Available from: http://www.globalhealthaction.net/index.php/gha/article/view/ 24488 [Accessed: 8th December 2015].

[10] Aryal UR, Bhatta DN, Shrestha N, Gautam A. Assessment of nicotine dependence among smokers in Nepal: a community based cross-sectional study. Tobacco Induced Diseases 2015. 13:26. Available from: $\mathrm{http}: / /$ tobaccoinduceddiseases.biomedcentral.com/articles/10.1 186/s12971-015-0053-8. [Accessed: 7th December 2015].

[11] Dhungana RR, Khanal MK, Baniya A. Prevalence of current tobacco use among secondary students in Nepal: a metaanalysis. Journal of Chitwan Medical College 2013. 3 (6). P: $1-5$.

[12] Khanal V, Adhikari M, Karki S. Social determinants of tobacco consumption among Nepalese men: findings from Nepal Demographic and Health Survey 2011. Harm Reduction Journal 2013. 10:40. Available from: $\mathrm{http} / / /$ harmreductionjournal.biomedcentral.com/articles/10.11 86/1477-7517-10-40. [Accessed: 10th December 2015].

[13] Narain R, Sardana S, Gupta S, Sehgal A. Risk factors associated with tobacco habits among adolescents: A crosssectional school-based study. The national medical journal of India 2013; 26 (4); p: 197-202.

[14] Palipudi KM, Gupta PC, Sinha DN, Andes LJ, Asma S, Mcafee T. Social Determinants of Health and Tobacco Use in Thirteen Low and Middle Income Countries: Evidence from Global Adult Tobacco Survey. PLOS ONE 2012; 7 (3) e33466. Available: http://dx.doi.org/10.1371/journal.pone.0033466. [Accessed: 2nd February 2016].

[15] Singh N, Tamrakar N. Practices and attitudes towards tobacco use among the employees of a private organization in Nepal. Nepal Med Coll J 2012. 14 (4). P: 312-315.

[16] Sreeramareddy CT, Ramakrishnareddy N, Kumar HNH, Sathian B, Arokiasamy JT. Prevalence, distribution and correlates of tobacco smoking and chewing in Nepal: a secondary data analysis of Nepal Demographic and Health Survey-2006. Sreeramareddy et al. Substance Abuse Treatment, Prevention, and Policy 2011; 6:33 Available from: http://www.substanceabusepolicy.com/content/6/1/33. [Accessed: 26th February 2016].

[17] Binu VS, Subba SH, Menezes RG, Kumar G, Ninan J, Rana MS, Chhetri SK, Sabu KM, Nagraj K. Smoking among Nepali youth--prevalence and predictors. Asian Pac J Cancer Prev.2010; 11 (1). p: 221-6.

[18] Echer IC, Correa APA, Lucena AF, Ferreira SAL, Knorst MM. Prevalence of Smoking among employees of a University Hospital. Rev. Latino-Am. Enfermagem 2011; 19 (1) p: $179-86$.

[19] Niraula SR. Tobacco Use among Women in Dharan, Eastern Nepal. J Health Popul Nutr 2004; 22 (1); p:68-74. 
[20] Subba SH, Binu VS, Menezes RG, Ninan J, Rana MS. Tobacco Chewing and Associated Factors Among Youth of Western Nepal: A Cross-sectional Study. Indian J Community Med. 2011; 36 (2); p: 128-32.

[21] Mao A, Yang T, Bottorff JL, Sarbit G. Personal and social determinants sustaining smoking practices in rural china: a qualitative study. International Journal for equity in health 2014. 13 (12).

[22] Lalithambigai G, Rao A, Rajesh G, Ramya S, Pai BHM. Predictors of Cigarette Smoking among Young Adults in
Mangalore, India. Asian Pacific Journal of Cancer Prevention 2016; 17 (1), p: 45-50.

[23] Shomar RTA, Lubbad IK, Ansari WEI, Al-khatib A, Alharazin HJ. Smoking, awareness of smoking-associated health risks, and knowledge of national legislation in Gaza Palestine. Cent Eur J Public Health 2014; 22 (2): 80-89.

[24] Narain R, Sardana S, Gupta S, Sehgal A. Age at initiation and prevalence of tobacco use among school children in Noida, India: A cross-sectional questionnaire based survey. Indian $\mathbf{J}$ Med Res 2011; 133 (3); p: 300-307. 